\title{
THE QUANTIFICATION OF THE CARTOGRAPHIC INFORMATION
}

\begin{abstract}
The article contains methods for conducting and results of research on the optimization of the navigation charts scale. The methodology is based on the principles of information theory. The basis for the calculation were the data read from the Polish charts. Certain been recommended optimal scales of the navigation charts.
\end{abstract}

\section{Keywords:}

maritime navigation, marine cartography, chart preparation.

\section{EMPIRICAL DATA OF THE AREA LOAD OF THE POLISH NAVIGATION CHARTS}

\section{Measurements of the area load of the Polish navigation charts}

Based on the measurements of the area load Polish navigation charts were obtained the following results are the basis for further studies.

1. The area load of Polish navigation charts of the southern part of the Middle Baltic (Polish coast and neighboring countries) is high. Number of cartographic symbols per $100 \mathrm{~cm}^{2}$ of the navigation charts is:

- for the open sea 50-100 conventional signs;

- for the coastal zone 150-200 signs;

- for the boundary complex forms 250-300 symbols;

- for large ports 450-550 conventional signs. 
Thus, the load intensity in the second, third and fourth case is approximately 3, 4 and 7 times greater than depicted on the navigation charts of the open sea.

2. As a cartographic symbols for navigation charts are used:

- mostly linear symbols (about 50\% parts),

- equally (20\%-25\%) point symbols and area symbols.

3. Analysis of navigation charts area load, carried out on the example of the Gulf of Gdansk, has indicated a strong influence of the purposeful generalization during a composition charts of the intensely developed areas:

- navigation charts at a scale of 1:50 000 contain about 4 thousand cartographic signs per 100 square nautical miles;

- navigation charts on a scale 1:100 000 contain about 1,5 thousand marks on 100 square nautical miles, which is about $38 \%$ of the marks allocated to this surface as illustrated by maps at a scale of 1:50 000;

- navigation charts on a scale 1: 250000 contain about 0,5 thousand marks per 100 square nautical miles, which is about $33 \%$ of the marks attributed to the surface as illustrated by maps on a scale 1:100 000, and about $13 \%$ of the number of characters on the maps at a scale of 1:50 000 .

4. Reducing the scale of the chart during a cartographic generalization $\left(M_{a} / M_{i}\right)$ theoretically would be expected decrease in the number of cartographic symbols respectively:

- up to $25 \%$ at $M_{\mathrm{a}}=150000$ and $M_{\mathrm{i}}=1000000$;

- up to $4 \%$ at $M_{\mathrm{a}}=1: 50000$ and $M_{\mathrm{i}}=1: 250000$.

Clearly the differences point to the dominant influence of the purposeful generalization on the charts. This phenomenon is mainly due to the nature of the navigation charts as thematic maps intended for a selected team of specialists.

\section{THE ANALYTICAL MODEL OF POLISH NEVIGATION CHARTS GENERALIZATION}

The collected empirical data allow you to show the discrete cartographical signs (point) as a function approximating their course. This is important for:

- the possibility of a smooth change of scale imaging and navigation chart;

- practical quantification of chart's images. 
Data can be presented in the form of Table 1 connecting the chart relative scale $\left(M_{\mathrm{a}} / M_{\mathrm{i}}\right)=x_{0}$ and the number of registered objects $N=y_{0}$.

Tab. 1. The area load of Polish navigation charts in function of their scale

\begin{tabular}{|c|c|}
\hline$M_{\mathrm{a}} / M_{\mathrm{i}}$ & $N[\mathrm{k}]$ \\
\hline$x_{0}=1$ & $y_{0}=4$ \\
\hline$x_{1}=2$ & $y_{1}=1.5$ \\
\hline$x_{2}=5$ & $y_{2}=0.5$ \\
\hline
\end{tabular}

Analytical form you can get a variety of methods, due to the small number of data contained in the array is proposed to apply the homographic functions.

Due to the dependence of area load charts on the scale, having only 3 pairs of data it has proposed to simplify the form, the host factor $c=1$. After substituting the data obtained the following equation describing the number of conventional signs on the waters of 100 square nautical miles as a function of the relative scales

$$
N=\frac{-0.038\left(\frac{M_{a}}{M_{i}}\right)+2.5}{\left(\frac{M_{a}}{M_{i}}\right)-0.385}[\mathrm{k}] .
$$

If hypothetically consider only the scale generalization, the number of conventional signs has been described by the following equation

$$
N_{s}=\frac{-0.235\left(\frac{M_{a}}{M_{i}}\right)+1.882}{\left(\frac{M_{a}}{M_{i}}\right)-0.588}[\mathrm{k}] .
$$

In turn, the number of cartographic symbols 'added' as a result of generalization thematic, as the difference $N_{t}=N-N_{s}$ can be described as binomial:

$$
N_{t}=\frac{0.197 x^{2}+0.549 x+0.670}{x^{2}-0.883 x+0.181} \quad[\mathrm{k}] .
$$

This function increases and reaches a maximum at point $\left(M_{a} / M_{i}\right) \approx 1.5$ which corresponds to chart scale 1:75 000.

Then slowly already decreases asymptotically parallel to $N_{\mathrm{s}}$. 


\section{DESCRIPTION OF CARTOGRAPHIC GENERALIZATION THROUGH EQUATIONS OF THE FIRST DEGREE}

\section{Assumptions of cartographic generalization}

The process of cartographic generalization combines contradictions. On the one hand, should meet the requirements for minimizing losses cartographic information, and on the other hand, should ensure the emergence of all the most important relationships between objects, which does not coincide with the principle of the diversity of content generalization.

The contradiction is in contrast purposes of generalization associated with a reduction scale of the chart and number of objectives related to the reduction of detail of the chart.

Exact analytical presentation and description of the generalization is labor-intensive process and not fully solved theoretically. In the general case, the process of generalization is proposed to be described by a differential equation containing partial derivatives of the first order type

$$
\mathrm{F}\left(x, y, \frac{M_{a}}{M_{i}}, \mathrm{u}, \frac{\partial u}{\partial x}, \frac{\partial u}{\partial y}, \frac{\partial u}{\partial \frac{M_{a}}{M_{i}}}\right)=0
$$

where:

$x, y \quad$ Cartesian coordinates,

$\mathrm{u}$ - function of generalization,

$\frac{\partial u}{\partial x}, \frac{\partial u}{\partial y}$ - the derivatives of generalization function relative to the directions of rectangular coordinates,

$\frac{\partial u}{\partial \frac{M_{a}}{M_{i}}}$ - derivative of the generalization function relative to scale.

Regular solution to this equation will be a collection of three-dimensional space as a function of a linear reduction of scales. Three-dimensional surface can describe the density of bottom contours, character pitch point or line elements on the chart or the intensity of the other cartographical elements or phenomena. 


\section{Cartographical generalization of the line and area symbols}

In the process of generalization is done to simplify the contour and select items map content, which leads to simplification of the form of analytic functions describing their position in space. In this case, the general solution (envelope surface collection) can bring a linear function.

In this case, you can find the function of generalization for the case of linear symbols, taking into account the reduction of size of linear (and surface) symbols in the process of generalization.

The chart area load output (a generalized) can be characterized by the following indicators:

$N_{0} \quad$ - number of conventional signs,

$P_{0}=x_{0}, y_{0}$ - area of generalizing portion of the chart,

$\sigma=N_{0} / P_{0}-$ load density.

For elements (symbols) content decreasing in proportion to the reduction scale of the chart is proposed that the following relationships:

$$
\begin{aligned}
& N_{1}=u_{1} \sigma\left[\left(\frac{M_{a}}{M_{i}}\right) P_{0}\right], \\
& u_{1}=1+\mathrm{g}_{1}\left(\frac{M_{a}}{M_{i}}\right)
\end{aligned}
$$

where:

$N_{1} \quad$ - number of cartographic conventional signs emerging as a result of reducing the linear scale,

$u_{1} \quad$ - the value of function of linear elements generalization,

1 - constant of the scale generalization,

$\mathrm{g}_{1}\left(M_{\mathrm{a}} / M_{i}\right)$ - generalization function of linear elements,

$M_{\mathrm{a}} / M_{i} \quad$ - a reduction of linear scale in the process of generalization.

The chart area load by surface elements is proposed to be characterized by the following equations: 


$$
\begin{aligned}
& N_{2}=u_{2} \sigma\left[\left(\frac{M_{a}}{M_{i}}\right)^{2} P_{0}\right], \\
& u_{2}=1+\mathrm{g}_{2}\left(\frac{M_{a}}{M_{i}}\right)
\end{aligned}
$$

where:

$\mathrm{N}_{2}$

— number of cartographic elements appearing by reducing their surface area on the chart,

$u_{2} \quad$ - the value of function of area elements generalization,

1 - constant of the scale generalization,

$\mathrm{g}_{2}\left(M_{\mathrm{a}} / M_{i}\right)$ - generalization function of area elements and groups of point symbols.

\section{The linear approximation \\ of chart generalization function}

The function of generalization should be determined by experimenting as the aggregate value of the function of generalization of all types of conventional signs appearing on the original chart. The resulting value will indicate the proportions of content items, and thus the relative overload of some of them.

If, as a first approximation to propose the linear nature of the generalization and borderline generalized chart characterized by the following indicators:

$\sigma^{*}$ - load density borderline generalized chart, $M^{*}$ — the scale of the chart,

then generalized function can be described by the following equation:

$$
g=\frac{\frac{\sigma^{*}}{\sigma_{a}}-1}{1-\frac{M_{a}}{M^{*}}}\left[1-\left(\frac{M_{a}}{M_{i}}\right)\right] .
$$

The above equation is valid only within the range of scales $M_{a} \leq M_{i} \leq M^{*}$ and for the linear change of function generalization.

The number of cartographic symbols (area load maps) within the indicated range of scales can be determined from the following equation: 


$$
N=N_{0}\left(\frac{M_{a}}{M_{i}}\right)^{2}\left[1+k\left(1-\frac{M_{a}}{M_{i}}\right)\right],
$$

where:

$k$ - coefficient of generalizing chart content evaluated as a function of the scale quotient.

In the linear form will be equal

$$
k=\frac{\left(\sigma^{*}-\sigma_{a}\right) M^{*}}{\sigma_{a}\left(M^{*}-M_{a}\right)} .
$$

It is proposed to the assumed linear model generalization, the factor generalizing chart content satisfies certain restrictions:

1. Ratio of generalization map content can range limited by the condition $N \leq N_{0}$, which prevents an increase in the number of homogeneous cartographic signs in the process of generalization. The linear model is

$$
k \leq \frac{1+\left(\frac{M_{a}}{M_{i}}\right)}{\left(\frac{M_{a}}{M_{i}}\right)^{2}} .
$$

2. The second limitation imposed on the function of generalization requires that the density of conventional signs of area generalized chart does not exceed the limit value $\sigma_{\mathrm{gr}}$. With the assumed linear model:

$$
\lim _{M_{i} \rightarrow M_{g r}} g\left(\frac{M_{a}}{M_{i}}\right)=1 .
$$

3. In the case where

$$
k\left(\frac{M_{a}}{M_{i}}\right)=\text { const. and } \mathrm{d} k\left(\frac{M_{a}}{M_{i}}\right)=0,
$$

we are dealing with a linear coefficient of increasing generalization of the payload applicable within the range of scales generalization. 


\section{THE QUANTIFICATION LEVELS OF CARTOGRAPHIC INFORMATION IN THE PROCESS OF GENERALIZATION OF POLISH NAVIGATION CHARTS}

\section{Intensity of contents generalization of the Polish charts}

The density of the conventional signs on the Polish navigation charts changes both under the influence of scaling generalization, and purposeful generalizations of the chart content. Previously prepared paper and electronic maps meet the standards and probably a long time yet remain so. However, we should consider the possibility of variable generalizing chart content or even swept the generalization of small scale intervals. The number of cartographic symbols can be described by the formula

$$
N=\frac{-0.038\left(\frac{M_{a}}{M_{i}}\right)+2.5}{\left(\frac{M_{a}}{M_{i}}\right)-0.385}[\mathrm{k}]
$$

As you can see the number of conventional signs per 100 square nautical miles decreases not linearly but hyperbolically. Speed on decrease the number of symbols can be characterized by the first derivative of numerous signs with respect to the denominators of scale map

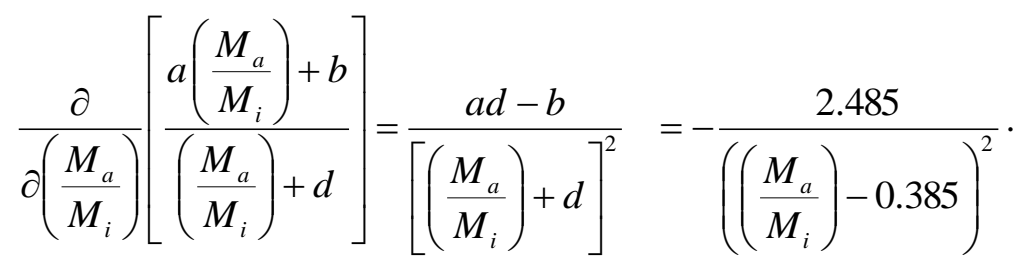

Previously obtained empirical data can be presented in the following Table

Tab. 2. Value of the derivative of number of cartographic symbols per 100 square nautical miles as a function of the relative scales

\begin{tabular}{|c|c|}
\hline$M_{\mathrm{a}} / M_{i}$ & $\partial / \partial\left(M_{a} / M_{i}\right)$ \\
\hline 1 & -3.97 \\
\hline 2 & -1.52 \\
\hline 3 & -0.94 \\
\hline 4 & -0.69 \\
\hline 5 & -0.54 \\
\hline
\end{tabular}


Based on these data, you can take 2 scale ranges:

- from $M_{\mathrm{a}} / M_{\mathrm{i}}=1(1: 50000)$ to $M_{\mathrm{a}} / M_{\mathrm{i}}=3(1: 150000)$, where the density of characters wanes nonlinearly to a significant extent;

- from $M_{\mathrm{a}} / M_{\mathrm{i}}=3(1: 150000)$ to $M_{\mathrm{a}} / M_{\mathrm{i}}=5(1: 250000)$, where the density of characters wanes slowly, almost linearly.

\section{The quantifications levels of the Polish navigation charts scales}

Assuming the above assumptions can confirm the desirability of the consequences of the use of scales:

$M_{\mathrm{a}} / M_{\mathrm{i}}=3$ - the scale of $1: 150000$,

$M_{\mathrm{a}} / M_{\mathrm{i}}=4$ - the scale 1: 200000 ,

$M_{\mathrm{a}} / M_{\mathrm{i}}=5$ - the scale of $1: 250000$.

In terms of scale between $M_{\mathrm{a}} / M_{\mathrm{i}}=1$ - scale 1:50 000 and $M_{\mathrm{a}} / M_{\mathrm{i}}=3$ - scale 1:150 000, it is appropriate to make a more dense distribution of intensity on decrease, taking into account the density of characters per 100 square nautical maps. Load density of charts can be transformed to the following form

$$
\frac{M_{a}}{M_{i}}=\frac{2.5+0.385 N}{N+0.038},
$$

which allows the identification of the following scale thresholds presented in the following Table

Tab. 3. Proposals of the scale quantification of navigation charts as a function of the number of cartographic symbols per 100 square nautical miles

\begin{tabular}{|c|c|c|}
\hline$N[\mathrm{k}]$ & $M_{a} / M_{i}$ & $M_{i}$ \\
\hline 4 & 1 & $1: 50000$ \\
\hline 3.5 & 1.06 & $1: 53000$ \\
\hline 3.0 & 1.22 & $1: 60000$ \\
\hline 2.5 & 1.38 & $1: 69000$ \\
\hline 2.0 & 1.60 & $1: 80000$ \\
\hline 1.5 & 2 & $1: 100000$ \\
\hline 1.13 & 2.5 & $1: 125000$ \\
\hline 0.9 & 3 & $1: 150000$ \\
\hline
\end{tabular}

The results obtained in the present study may provide a basis for rationalizing the preparation of cartographic materials for the purpose of conducting marine navigation. 


\section{REFERENCES}

[1] Kołaczyński S., Attribute of the navigation as technical discipline [in Polish], 'Geodezja i Kartografia', 1987, Vol. XXXVI, pp. 283-289.

[2] Kołaczyński S., The expository content of rectangular coordinates on the surface of the sphere [in Polish], 'Zeszyty Naukowe WSGK', Kutno 2005, pp. 225-235.

[3] Kołaczyński S., The expository content of results of controlled measurement of the depth [in Polish], 'Zeszyty Naukowe AMW', 2013, No. 2, pp. 49-56.

Received July 2016

Reviewed December 2016

\section{STANISŁAW KOLACZYŃSKI}

Polish Naval Academy

Śmidowicza 69 Str., 81-127 Gdynia, Poland

e-mail: s.kolaczynski@amw.gdynia.pl

\section{STRESZCZENIE}

Artykuł zawiera metodykę prowadzenia i wyniki badań dotyczących optymalizacji skali kartograficznych map nawigacyjnych. Metodyka oparta została na założeniach teorii informacji. Podstawę obliczeń stanowiły dane odczytane z polskich map. Określone zostały zalecane optymalne skale map nawigacyjnych. 